\title{
Angiotensin II impairs endothelial function via tyrosine phosphorylation of the endothelial nitric oxide synthase
}

\author{
Annemarieke E. Loot, ${ }^{1}$ Judith G. Schreiber, ${ }^{2}$ Beate Fisslthaler, ${ }^{1}$ \\ and Ingrid Fleming ${ }^{1}$
}

IInstitute for Vascular Signaling, Center for Molecular Medicine and ${ }^{2}$ nstitute for Cardiovascular Physiology, Johann Wolfgang Goethe University, 60590 Frankfurt am Main, Germany

Proline-rich tyrosine kinase 2 (PYK2) can be activated by angiotensin II (Ang II) and reactive oxygen species. We report that in endothelial cells, Ang II enhances the tyrosine phosphorylation of endothelial $\mathrm{NO}$ synthase (eNOS) in an $\mathrm{AT}_{1}-, \mathrm{H}_{2} \mathrm{O}_{2}-$, and PYK2-dependent manner. Low concentrations (1-100 $\mu \mathrm{mol} / \mathrm{liter})$ of $\mathrm{H}_{2} \mathrm{O}_{2}$ stimulated the phosphorylation of eNOS Tyr657 without affecting that of Ser1177, and attenuated basal and agonist-induced $\mathrm{NO}$ production. In isolated mouse aortae, $30 \mu \mathrm{mol} / \mathrm{liter} \mathrm{H}_{2} \mathrm{O}_{2}$ induced phosphorylation of eNOS on Tyr657 and impaired acetylcholine-induced relaxation. Endothelial overexpression of a dominant-negative PYK2 mutant protected against $\mathrm{H}_{2} \mathrm{O}_{2}$ induced endothelial dysfunction. Correspondingly, carotid arteries from eNOS ${ }^{-1-}$ mice overexpressing the nonphosphorylatable eNOS Y657F mutant were also protected against $\mathrm{H}_{2} \mathrm{O}_{2}$. In vivo, 3 wk of treatment with Ang II considerably increased levels of Tyr657phosphorylated eNOS in the aortae of wild-type but not Nox2 ${ }^{y /-}$ mice, and this was again associated with a clear impairment in endothelium-dependent vasodilatation in the wildtype but not in the Nox $2^{y /-}$ mice. Collectively, endothelial PYK2 activation by Ang II and $\mathrm{H}_{2} \mathrm{O}_{2}$ causes the phosphorylation of eNOS on Tyr657, attenuating NO production and endothelium-dependent vasodilatation. This mechanism may contribute to the endothelial dysfunction observed in cardiovascular diseases associated with increased activity of the renin-angiotensin system and elevated redox stress.

CORRESPONDENCE

Annemarieke Loot:

Loot@vrc.uni-frankfurt.de

Abbreviations used: ACh, acetylcholine; Ang II, angiotensin II; $\mathrm{DN}$, dominant negative; eNOS, endothelial NO synthase; PEG, polyethylene glycol; PYK2, proline-rich tyrosine kinase 2.
Endothelial dysfunction is recognized as an independent risk factor for the development of cardiovascular diseases, and is characterized by a reduced bioavailability of the antithrombotic and antiatherosclerotic autacoid NO (Davignon and Ganz, 2004). The decrease in NO is directly related to increased vascular oxidative stress, as $\mathrm{O}_{2}{ }^{-}$readily reacts with $\mathrm{NO}$ to form peroxynitrite. Perhaps more importantly, the oxidative depletion of tetrahydrobiopterin causes the so-called uncoupling of endothelial NO synthase (eNOS), leading to the production of $\mathrm{O}_{2}{ }^{-}$ instead of NO by the enzyme (Schulz et al., 2008). Despite the undisputed role of oxidative stress in the etiology of endothelial dysfunction, large clinical trials with antioxidant therapies have failed to show a beneficial effect on cardiovascular outcome (Thomson et al., 2007). This discrepancy is probably explained at least in part by the formation of other reactive oxygen species from $\mathrm{O}_{2}{ }^{-}$that have more complex roles in intracellular signaling beyond $\mathrm{NO}$ scavenging. Several superoxide dismutases convert $\mathrm{O}_{2}{ }^{-}$to the more stable $\mathrm{H}_{2} \mathrm{O}_{2}$ that has widespread and more prolonged effects on endothelial cell function (for review see Cai, 2005). $\mathrm{H}_{2} \mathrm{O}_{2}$ is in turn eliminated through the actions of catalase and peroxidases. However, it is important to note that the exogenous application of catalase can ameliorate endothelial dysfunction in some models of hypertension (Ulker et al., 2003), whereas catalase aggravates the situation in models characterized by the uncoupling of eNOS (Landmesser et al., 2003). To date, several studies have reported that promoting the conversion of $\mathrm{O}_{2}{ }^{-}$to $\mathrm{H}_{2} \mathrm{O}_{2}$ to relieve $\mathrm{NO}$ scavenging does not prevent the

\footnotetext{
2009 Loot et al. This article is distributed under the terms of an Attribution-Noncommercial-Share Alike-No Mirror Sites license for the first six months after the publication date (see http://www.jem.org/misc/terms.shtml). After six months it is available under a Creative Commons License (Attribution-Noncommercial-Share Alike 3.0 Unported license, as described at http://creativecommons org/licenses/by-nc-sa/3.0/).
} 
formation of atherosclerotic lesions and that superoxide dismutase activity actually correlates with lesion size (Tribble et al., 1997; Zanetti et al., 2001). These observations suggest that the impairment of eNOS activity by oxidative stress is more complex than hitherto assumed.

We recently reported that Tyr657 in the reductase domain of eNOS is a critical determinant of enzymatic activity. For example, the phosphorylation of Tyr657 by proline-rich tyrosine kinase 2 (PYK2) decreases eNOS activity, and the mutation of Tyr657 to a phosphomimetic glutamate or aspartate residue completely abolished NO production (Fisslthaler et al., 2008). PYK2 is generally considered to be a redox-sensitive kinase that is activated after stimulation with angiotensin II (Ang II) as well as in other situations associated with elevated oxidative stress (Tai et al., 2002; Yin et al., 2003). As elevated Ang II levels and increased oxidative stress are hallmarks of most cardiovascular diseases and associated with impaired endothelial function, we hypothesized that direct inactivation of eNOS via its tyrosine phosphorylation by PYK2 contributes to the phenomenon of endothelial dysfunction.

\section{RESULTS AND DISCUSSION}

Ang II and $\mathrm{H}_{2} \mathrm{O}_{2}$ induce activation of endothelial PYK2 and phosphorylation of eNOS on Tyr657, and decrease eNOS activity

In native porcine aortic endothelial cells, $1 \mu \mathrm{mol} /$ liter Ang II elicited the time-dependent tyrosine phosphorylation of PYK2 (Fig. 1 A), which correlates with the activation of the kinase (Blaukat et al., 1999). The exogenous application of $500 \mu \mathrm{mol} /$ liter $\mathrm{H}_{2} \mathrm{O}_{2}$ also resulted in PYK2 phosphorylation (Fig. 1 A). Moreover, the activation of PYK2 by Ang II and $\mathrm{H}_{2} \mathrm{O}_{2}$ was mirrored by a pronounced increase in the phosphorylation of eNOS on Tyr657 (Fig. 1 B).
Mouse lung endothelial cells, which maintain responsiveness to Ang II in culture, were used to analyze the pathway leading to eNOS Tyr657 phosphorylation by Ang II. As was the case with the native porcine endothelial cells, 100 nmol/liter Ang II induced the phosphorylation of eNOS on Tyr657, and this was directly dependent on PYK2 activation because Ang II failed to increase eNOS phosphorylation in endothelial cells pretreated with PYK2 siRNA (Fig. 2 A). Furthermore, the activation of PYK2 by Ang II was prevented by $10 \mu \mathrm{mol} /$ liter telmisartan (Fig. $2 \mathrm{~B}$ ), demonstrating the involvement of the $\mathrm{AT}_{1}$ receptor. Ang II-induced $\mathrm{H}_{2} \mathrm{O}_{2}$ production seems to underlie the activation of PYK2, as the addition of Ang II to mouse lung endothelial cells resulted in the production of $\mathrm{H}_{2} \mathrm{O}_{2}$ (Fig. S1), and $150 \mathrm{U} / \mathrm{ml}$ polyethylene glycol (PEG)-catalase prevented the Ang II-induced phosphorylation of PYK2 as well as the subsequent phosphorylation of eNOS (Fig. 2, C and D). Collectively, these data indicate that Ang II induces eNOS Tyr657 phosphorylation through an $\mathrm{AT}_{1}$ receptor- $\mathrm{H}_{2} \mathrm{O}_{2^{-}}$, and PYK2dependent mechanism.

Incubation of cultured human endothelial cells with $\mathrm{H}_{2} \mathrm{O}_{2}$ for $5 \mathrm{~min}$ also elicited the tyrosine phosphorylation of eNOS. The latter response was detectable at concentrations as low as $100 \mathrm{nmol} /$ liter (Fig. $3 \mathrm{~A}$ ). At high concentrations (300-500 $\mu \mathrm{mol} /$ liter), however, $\mathrm{H}_{2} \mathrm{O}_{2}$ stimulates the influx of $\mathrm{Ca}^{2+}$ into endothelial cells (Edwards et al., 2008), and this was associated with the phosphorylation of eNOS on Ser1177 (Fig. 3 A). This dual effect on eNOS phosphorylation was also reflected by changes in eNOS activity. At low concentrations (e.g., $30 \mu \mathrm{mol} /$ liter), $\mathrm{H}_{2} \mathrm{O}_{2}$ inhibited basal eNOS activity, whereas high concentrations (300-500 $\mu \mathrm{mol} / \mathrm{liter})$ stimulated NO production (Fig. $3 \mathrm{~B}$ ). The latter phenomenon has also been reported by other authors (Thomas et al.,
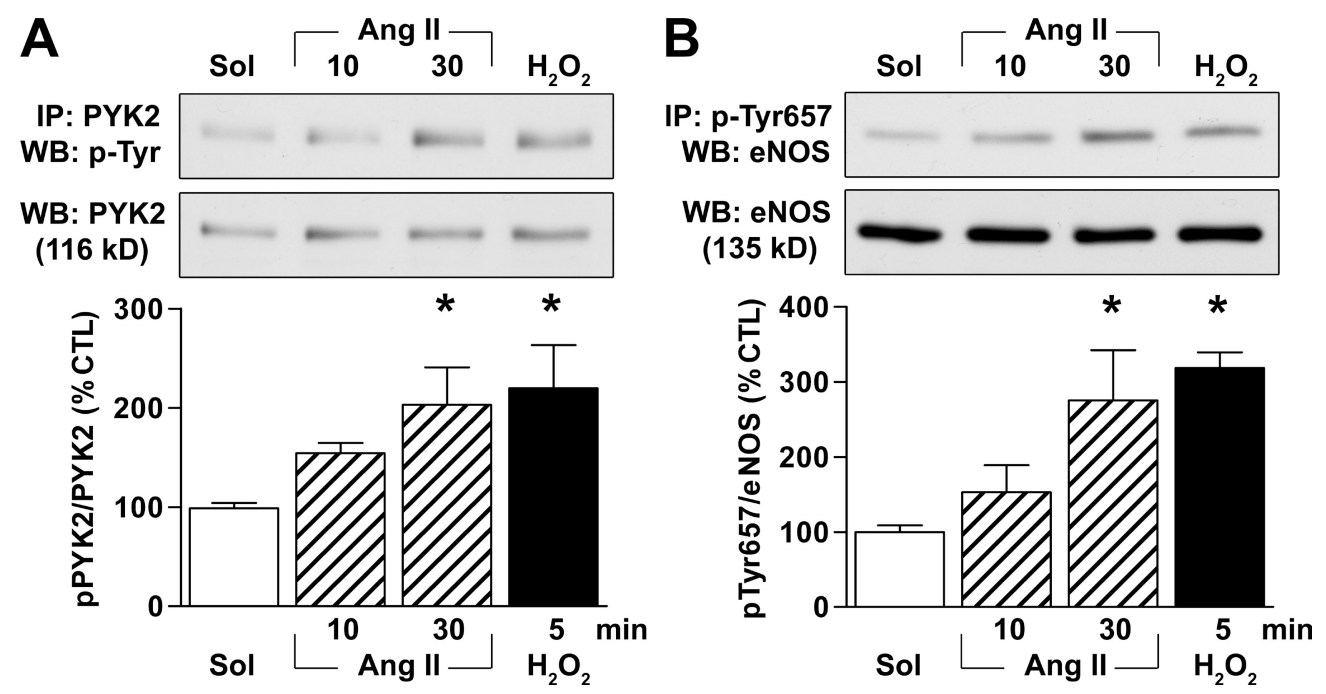

Figure 1. Ang II and $\mathrm{H}_{2} \mathrm{O}_{2}$ activate PYK2 and phosphorylate eNOS on Tyr657. (A and B) Porcine aortae were incubated with solvent (Sol), $1 \mu$ mol/ liter Ang II, or $500 \mu \mathrm{mol} /$ liter $\mathrm{H}_{2} \mathrm{O}_{2}$. The endothelial cells were isolated, and the tyrosine phosphorylation of PYK2 (A) and the phosphorylation of eNOS on Tyr657 (B) were assessed by immunoprecipitation (IP) followed by Western blotting (WB). The graphs summarize data from six samples from three independent experiments. Data are expressed as means \pm SEM. ${ }^{*}, \mathrm{P}<0.05$ versus solvent. 
2002; Dossumbekova et al., 2008). To circumvent this confounding effect in further experiments, we concentrated on determining the responses to a maximum $\mathrm{H}_{2} \mathrm{O}_{2}$ concentration of $30 \mu \mathrm{mol} /$ liter. At this low and potentially physiologically more relevant concentration, $\mathrm{H}_{2} \mathrm{O}_{2}$ significantly attenuated the activation of eNOS by bradykinin and ionomycin (Fig. 3 C). Furthermore, incubation of freshly isolated endothelium-intact mouse aortae with $30 \mu \mathrm{mol} /$ liter $\mathrm{H}_{2} \mathrm{O}_{2}$ for $10 \mathrm{~min}$ induced the phosphorylation of eNOS on Tyr657 (Fig. 4 A). This concentration of $\mathrm{H}_{2} \mathrm{O}_{2}$ elicited only a small nonsignificant $(10.7 \pm 5.8 \% ; n=7 ; \mathrm{P}=0.068)$ decrease of vascular tone (which was corrected for by using the new plateau as a baseline) and significantly impaired endothelium- dependent relaxation to acetylcholine (ACh; Fig. 4 B). To the best of our knowledge, the present investigation is the first to assess $\mathrm{NO}$ production in response to such a large range of $\mathrm{H}_{2} \mathrm{O}_{2}$ concentrations and to correlate these changes with the activity as well as the phosphorylation of eNOS on more than one regulatory site.

The impairment of NO-mediated vasodilatation by $\mathrm{H}_{2} \mathrm{O}_{2}$ is PYK2 dependent

It is clear that $\mathrm{H}_{2} \mathrm{O}_{2}$ can potentially affect the eNOS/cyclic GMP signaling cascade and subsequent vasodilatation at several different levels. In addition to stimulating the phosphorylation of eNOS, $\mathrm{H}_{2} \mathrm{O}_{2}$ can alter the activity of the soluble
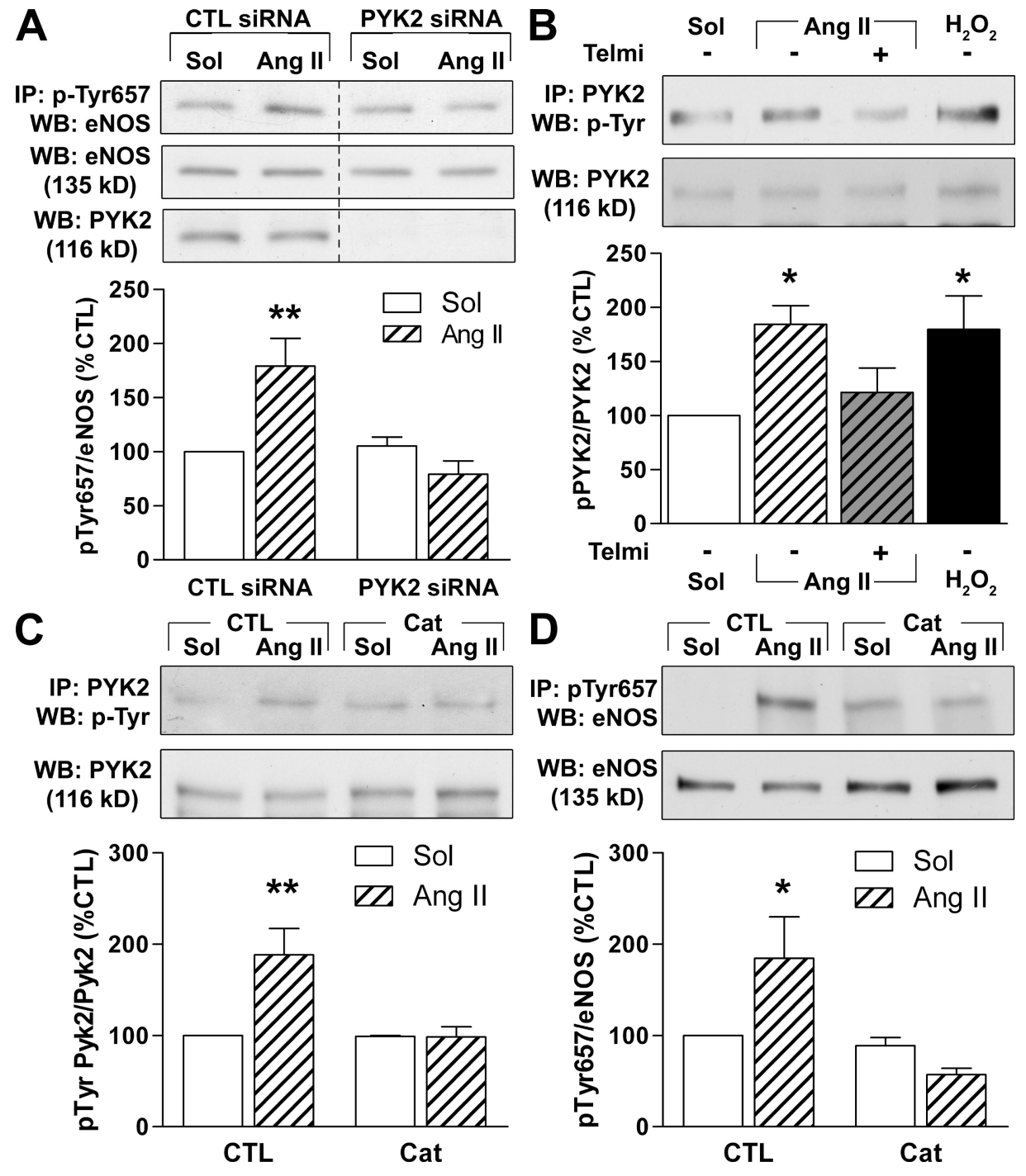

Figure 2. Ang II phosphorylates eNOS on Tyr657 by activation of $\mathrm{AT}_{1}, \mathrm{H}_{2} \mathrm{O}_{2}$, and PYK2. (A) Mouse lung endothelial cells were transfected with a scrambled (CTL) siRNA or siRNA directed against PYK2 $48 \mathrm{~h}$ before incubation with $100 \mathrm{nmol} /$ liter Ang II. Thereafter, eNOS phosphorylated on Tyr657 was immunoprecipitated (IP) and detected by Western blotting (WB). Nonadjacent lanes from the same membrane and exposition are shown. (B) Effect of 100 nmol/liter Ang II for 30 min, Ang II and $10 \mu \mathrm{mol} /$ liter telmisartan (Telmi), or $30 \mu \mathrm{mol} / /$ iter $\mathrm{H}_{2} \mathrm{O}_{2}$ for 5 min on the tyrosine phosphorylation of PYK2. (C and D) Mouse lung homogenates were incubated with $150 \mathrm{U} / \mathrm{ml} \mathrm{PEG-catalase} \mathrm{(Cat)} \mathrm{for} 1 \mathrm{~h}$ before stimulation with $100 \mathrm{nmol} /$ liter Ang II for $20 \mathrm{~min}$. The tyrosine phosphorylation of PYK2 (C) and eNOS (D) were assessed by immunoprecipitation and Western blotting. The graphs summarize data from six samples from three to six independent experiments. Data are expressed as means $\pm \mathrm{SEM} .{ }^{*}, \mathrm{P}<0.05$; and ${ }^{*}, \mathrm{P}<0.01$ versus the corresponding solvent (Sol) control. 
guanylyl cyclase (Meurer et al., 2005), as well as of several other tyrosine kinases and tyrosine phosphatases. To relate the decreased endothelium-dependent relaxation to the activation of PYK2, responses to ACh were compared in carotid arteries from wild-type mice in which the endothelial layer was infected with adenoviruses to overexpress either GFP or a dominant-negative (DN) PYK2. Although endothelial infection followed by organ culture is a simple method and allows the transduction of many proteins of interest, including "rescue" experiments in tissues from knockout mice, it is not free of complications. Indeed, we observed that the maintenance of carotid arteries in culture for $48 \mathrm{~h}$ led to a significant increase in the endogenous production of $\mathrm{H}_{2} \mathrm{O}_{2}$ that was not affected by the expression of GFP or DN PYK2 (Fig. S2 top). Correspondingly, responses to ACh in solvent-treated arteries expressing GFP were moderately impaired (maximal response $=68 \pm 7 \%$; Fig. $5 \mathrm{~A}$; in comparison, freshly isolated wild-type arteries typically relax to $90 \%$; Fig. 4 B). However, the exogenous application of $30 \mu \mathrm{mol} /$ liter $\mathrm{H}_{2} \mathrm{O}_{2}$ further impaired endothelium-dependent relaxations (Fig. 5 A). Overexpression of the DN PYK2 mutant significantly improved ACh-stimulated responses in solvent-treated arteries (maximal response $=83 \pm 4 \%$ ) and completely protected the arteries against the effect of exogenous $\mathrm{H}_{2} \mathrm{O}_{2}$ (Fig. $5 \mathrm{~B}$ ). Such findings indicate that PYK2 activation may underlie both the basal reduction in vascular responsiveness as well as the acute impairment of endothelial function elicited by the exogenous application of $\mathrm{H}_{2} \mathrm{O}_{2}$.

To demonstrate a causal relation between the phosphorylation of eNOS on Tyr657 and impaired endothelial function, experiments were repeated in carotid arteries from $\mathrm{eNOS}^{-1-}$ mice overexpressing either the wild-type eNOS or a nonphosphorylatable Y657F (tyrosine replaced by phenylalanine) eNOS mutant. Consistent with the endogenous $\mathrm{H}_{2} \mathrm{O}_{2}$ production in eNOS ${ }^{-/-}$carotid arteries after organ culture (Fig. S2 bottom), vessels transduced with wild-type eNOS relaxed to a maximum of only $50 \pm 4 \%$. The application of $\mathrm{H}_{2} \mathrm{O}_{2}$, however, further decreased endotheliumdependent relaxation in response to $\mathrm{ACh}$ (Fig. $5 \mathrm{C}$ ). In carotid arteries expressing similar levels of the Y657F eNOS mutant, relaxations to ACh were significantly improved under basal conditions (maximum relaxation $=79 \pm 6 \%$ ) and completely unaffected by exogenous $\mathrm{H}_{2} \mathrm{O}_{2}$ (Fig. 5 D). As organ culture enhanced endogenous $\mathrm{H}_{2} \mathrm{O}_{2}$ production in vessels from wild-type and $\mathrm{eNOS}^{-/-}$mice alike, it seems that the oxidant is generated by vascular sources other than
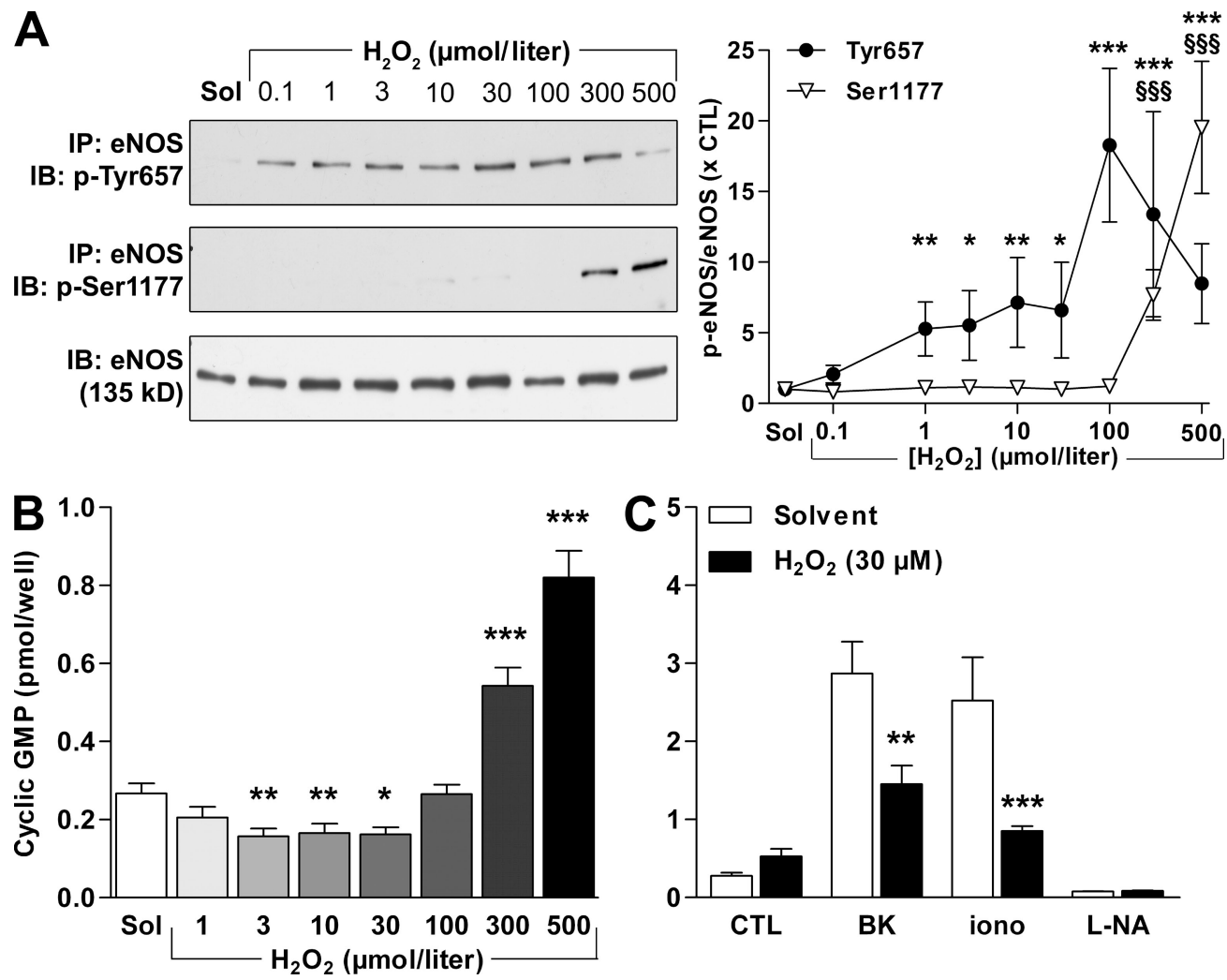

Figure 3. $\mathrm{H}_{2} \mathrm{O}_{2}$ has a dual effect on eNOS phosphorylation and activity. (A-C) Human endothelial cells were incubated with 0.1-500 $\mu \mathrm{mol} /$ liter $\mathrm{H}_{2} \mathrm{O}_{2}$ for 15 min. Thereafter, either (A) eNOS was immunoprecipitated (IP) and its phosphorylation on Tyr657 and Ser 1177 were detected by Western blotting (IB), or (B and C) cyclic GMP levels were assessed by radioimmunoassay under basal conditions (B) or after stimulation with $1 \mu \mathrm{mol} /$ liter bradykinin (BK) for $2 \mathrm{~min}$ or $100 \mathrm{nmol} /$ liter ionomycin (iono) for $2 \mathrm{~min}$ (C). Some experiments were also performed in the presence of $300 \mu \mathrm{mol} / /$ iter $\mathrm{N}^{\omega} \mathrm{nitro}-\mathrm{L}$-arginine (L-NA) for $60 \mathrm{~min}$. The graphs summarize data from 8-12 experiments. Data are expressed as means $\pm \mathrm{SEM}$. ${ }^{*}, \mathrm{P}<0.05{ }^{*}{ }^{*}, \mathrm{P}<0.01$; and ${ }^{* * *}, \mathrm{P}<$ 0.001 versus CTL or the corresponding solvent (Sol)-treated group. $\S \S \S, \mathrm{P}<0.001$ versus solvent for Ser 1177 phosphorylation. 
eNOS. Whatever the mechanism responsible, we observed that DN PYK2 was able to protect vessels against $\mathrm{H}_{2} \mathrm{O}_{2}-$ induced endothelial dysfunction as well as against the attenuated responsiveness to $\mathrm{ACh}$ that was associated with organ culture itself. As mutation of Tyr657 to the nonphosphorylatable phenylalanine conferred protection, it seems that phosphorylation rather than the uncoupling of eNOS accounts for the effects observed.

In addition to its effects on PYK2, $\mathrm{H}_{2} \mathrm{O}_{2}$ is reported to inactivate the protein tyrosine phosphatase SHP-2 (Tang et al., 2005). SHP-2 is of potential relevance to the current study because it is reported to deactivate PYK2 (Chauhan et al., 2000), and we have previously demonstrated that eNOS and SHP-2 can be coprecipitated from cultured endothelial

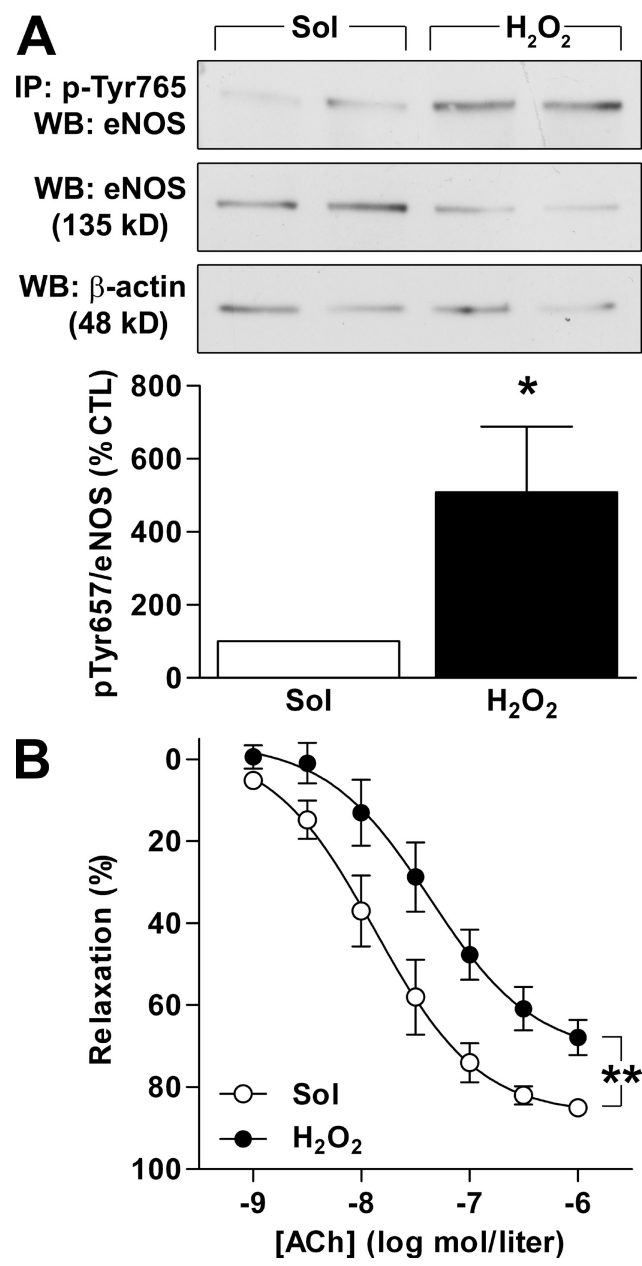

Figure 4. $\mathrm{H}_{2} \mathrm{O}_{2}$ induces Tyr657 phosphorylation and impairs endothelium-dependent vasodilatation in isolated mouse aorta. (A) Isolated aortae were incubated in the absence (Sol) or presence of 500 $\mu \mathrm{mol} /$ liter $\mathrm{H}_{2} \mathrm{O}_{2}$ for $10 \mathrm{~min}$, and phosphorylation of the immunoprecipitated (IP) eNOS on Tyr657 was detected by Western blotting (WB). (B) ACh-induced vasodilatation was assessed in the absence (Sol) or presence of $30 \mu \mathrm{mol} /$ liter $\mathrm{H}_{2} \mathrm{O}_{2}$ in aortic ring segments in the continuous presence of $10 \mu \mathrm{mol} /$ liter diclofenac. The graphs summarize the results obtained in 4-10 different experiments. Data are expressed as means \pm SEM. ${ }^{*}, \mathrm{P}<0.05 ;$ and ${ }^{*}, \mathrm{P}<0.01$ versus $\mathrm{CTL}$. cells (Dixit et al., 2005). However, as the reported $\mathrm{IC}_{50}$ value for the $\mathrm{H}_{2} \mathrm{O}_{2}$-induced inactivation of SHP-2 is $\sim 75 \mu \mathrm{mol} /$ liter, it seems unlikely that SHP-2 inactivation is the main mechanism by which $\mathrm{H}_{2} \mathrm{O}_{2}$ influences eNOS activity. At this stage, we cannot exclude the involvement of an additional phosphatase because $\mathrm{H}_{2} \mathrm{O}_{2}$ can result in the oxidation of the critical cysteine residues and, thus, inactivate a series of tyrosine phosphatases (Thomas et al., 2008). However, as the expression of DN PYK2 was sufficient to abrogate the $\mathrm{H}_{2} \mathrm{O}_{2}-$ induced endothelial dysfunction, we speculate that kinase activation is the predominant mechanism underlying the effects described.

\section{Chronic treatment with Ang II stimulates the phosphorylation of eNOS on Tyr657 and endothelial dysfunction}

Our results indicated that the phosphorylation of eNOS on Tyr657 is acutely related to a decrease in endothelial function, but the pathophysiological consequences of endothelial dysfunction (e.g., atherosclerosis) generally develop over prolonged periods. To determine the physiological relevance of the mechanism described, we assessed eNOS phosphorylation in aortae from mice treated with Ang II over $3 \mathrm{wk}$, a procedure previously shown to induce hypertension and vascular oxidative stress as well as endothelial dysfunction (Jung et al., 2005). In segments of aortae isolated from wild-type mice treated with $1 \mathrm{mg} / \mathrm{kg} /$ day Ang II for $3 \mathrm{wk}$, a clear impairment in endothelial function was observed (Fig. 6 A). Although eNOS expression was unaltered by the Ang II treatment, eNOS Tyr657 phosphorylation was significantly higher in the Ang II-treated group (Fig. 6 B).

Many of the consequences of Ang II exposure are related to the formation of reactive oxygen species, such as $\mathrm{H}_{2} \mathrm{O}_{2}$, as a consequence of the activation of NADPH oxidases (for review see Garrido and Griendling, 2009). In endothelial cells, Ang II activates mainly the Nox 2 (gp91phox) and Nox4 subunits, and the genetic disruption of Nox2 prevents the endothelial dysfunction observed in a high-renin model of hypertension (Jung et al., 2004). We therefore assessed eNOS phosphorylation in mice lacking the Nox2 subunit. Because the gene encoding Nox2 is located on the $\mathrm{X}$ chromosome, we compared male Nox2-deficient $\left(\operatorname{Nox}_{2}{ }^{\mathrm{y} /-}\right)$ mice to their wild-type (Nox $2^{\mathrm{y} /+}$ ) counterparts. We found that the treatment of Nox $2^{\mathrm{y} /-}$ mice with Ang II did not result in the attenuation of endotheliumdependent responses to ACh (Fig. $6 \mathrm{C}$ ) and did not increase eNOS phosphorylation on Tyr657 (Fig. 6 D).

Endothelium-derived NO is not only essential for controlling vascular tone but is also a critical determinant for vascular gene expression, the recruitment of circulating cells, and the progression of vascular diseases such as atherosclerosis and restenosis (Davignon and Ganz, 2004). Correspondingly, eNOS gene transfer is considered an attractive therapeutic option to improve endothelial function. However, although the exogenous expression of eNOS successfully prevented smooth muscle cell migration in vitro (Largiadèr et al., 2008), a similar approach in human atherosclerotic lesions failed because the heterologously expressed eNOS was inactive (Tanner et al., 2007). 

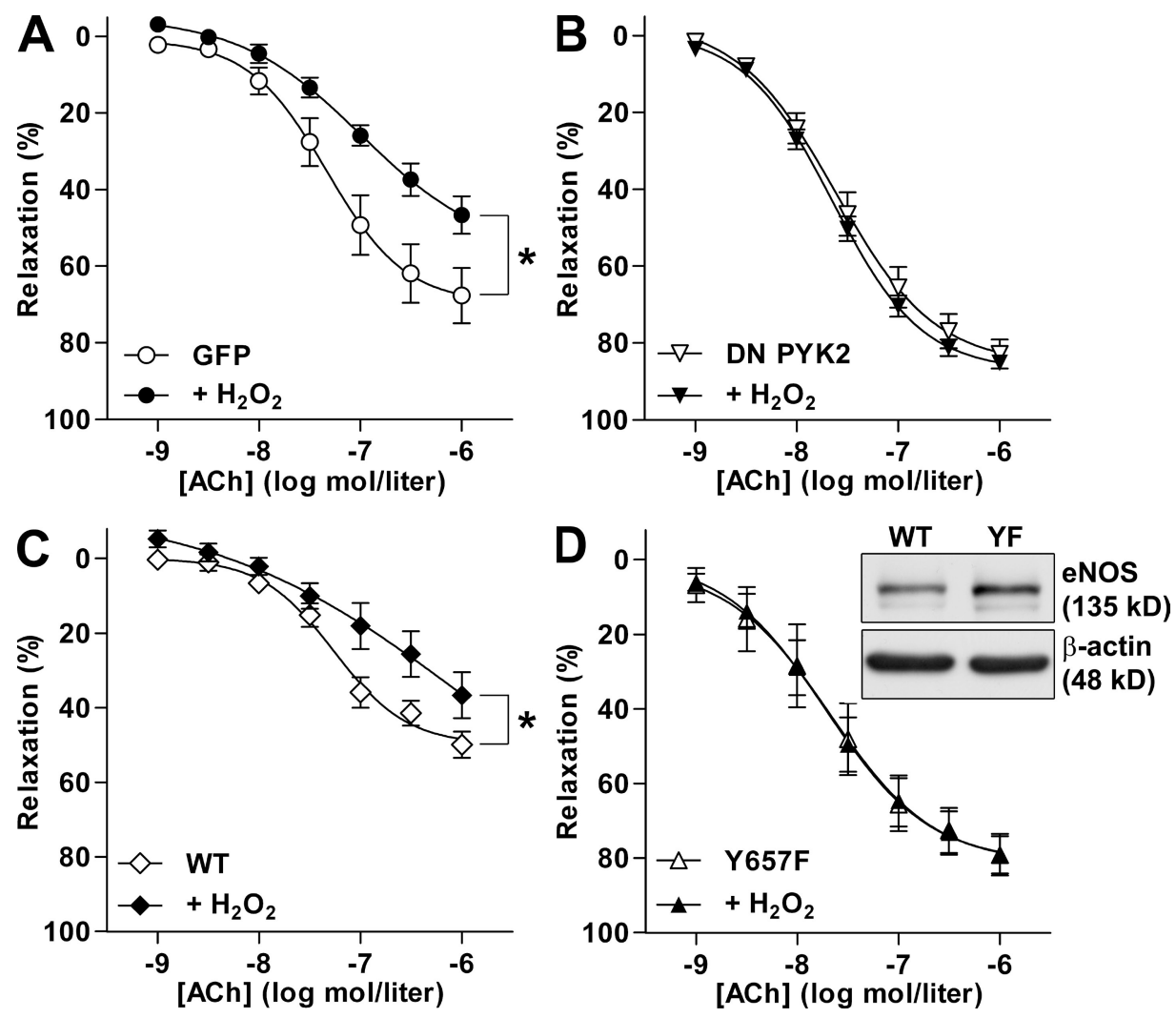

Figure 5. $\quad \mathrm{H}_{2} \mathrm{O}_{2}$-induced endothelial dysfunction involves PYK2 and eNOS phosphorylation on Tyr657. (A-D) ACh-induced vasodilatation was assessed in the absence or presence of $30 \mu \mathrm{mol} /$ liter $\mathrm{H}_{2} \mathrm{O}_{2}$ in carotid arteries from wild-type (A and B) or eNOS ${ }^{-1-}(\mathrm{C}$ and D) mice infected with adenoviruses to express GFP (A), a DN PYK2 mutant (B), wild-type eNOS (WT; C), or the Y657F eNOS mutant (YF; D). The inset shows expression of adenovirally delivered wild-type and Y657F eNOS. The graphs summarize the results obtained in six to eight different experiments. Data are expressed as means \pm SEM. ${ }^{*}, \mathrm{P}<0.05$ versus the appropriate solvent control.

In the latter study, the supplementation of samples with essential cofactors, including tetrahydrobiopterin and L-arginine, failed to stimulate NO production, indicating that mechanisms other than enzyme uncoupling determine NO production in atherosclerotic lesions. It is tempting to speculate that the inactivation of eNOS as a consequence of its phosphorylation by PYK2 may play an important role; certainly in the setting of atherosclerosis, PYK2 may be sufficiently activated to influence eNOS. Therefore, it follows that the expression of the nonphosphorylatable eNOS Y657F mutant could represent a more successful therapeutic approach.

\section{MATERIALS AND METHODS}

Materials. The mono-/polyclonal eNOS antibodies were from Santa Cruz Biotechnology, Inc.; the specific phospho-Tyr657 eNOS antibody was generated as previously described (Fisslthaler et al., 2008) by Eurogentec; and the anti-PYK2 antibody was from BD. Tyrosine-phosphorylated proteins were detected with a mixture of four antibodies: P-Tyr-100 (Cell Signaling Technology), Py20 (Santa Cruz Biotechnology, Inc.), Py20 (BD), and clone 4G10 (Millipore). All other substances were obtained from Sigma-Aldrich.

Cell culture. The use of human umbilical vein endothelial cells was approved by the ethics committee of the Johann Wolfgang Goethe University medical faculty. Human umbilical vein endothelial cells and mouse lung endothelial cells were isolated and cultured as previously described
(Fleming et al., 2005). In some experiments, cyclic GMP production was assessed with a specific radioimmunoassay (GE Healthcare), as previously described (Fisslthaler et al., 2008). To silence PYK2 gene expression, mouse lung endothelial cells were transfected with a mixture of siRNA duplexes (5'-AUCUGAGGCAGGCUGUUCCUCUUCU-3', 5'-UUUCGUUCCAGGUAGUGUCCCAGCU-3', and 5'-UUCUCCAGCACUCCGAUGACAUCCU-3'; Invitrogen) or with control oligonucleotides of medium GC content (Eurogentec).

Porcine aortae collected at the local slaughterhouse were cut open lengthwise, fixed in stainless steel frames containing Hepes-Tyrode solution, and incubated at $37^{\circ} \mathrm{C}$ for a total of $1 \mathrm{~h} .1 \mu \mathrm{mol} /$ liter Ang II was added 10 or $30 \mathrm{~min}$ before, and $500 \mu \mathrm{mol} /$ liter $\mathrm{H}_{2} \mathrm{O}_{2}$ was added $5 \mathrm{~min}$ before the end of the incubation period. Endothelial cells were recovered by scraping and centrifugation for $4 \mathrm{~min}$ at $4,000 \mathrm{rpm}$ and $4^{\circ} \mathrm{C}$.

Freshly isolated mouse lungs were cut into $\sim 1-\mathrm{mm}^{3}$ pieces, suspended in modified Tyrode's solution containing $100 \mu \mathrm{mol} /$ liter L-arginine, and equilibrated for $2 \mathrm{~h}$ in a normal $\mathrm{CO}_{2}$ incubator. $150 \mathrm{U} / \mathrm{ml}$ PEG-catalase was added as indicated in the figures for $1 \mathrm{~h}$ before stimulation with $100 \mathrm{nmol} /$ liter Ang II for $15 \mathrm{~min}$.

Immunoprecipitation and immunoblotting. Cells, isolated aortae, and lungs were lysed in Triton X-100 buffer. eNOS, tyrosine-phosphorylated proteins, or PYK2 were immunopreciptated with the appropriate antibodies. Detergent-soluble proteins or immunoprecipitates were heated with SDSPAGE sample buffer and separated by SDS-PAGE, and specific proteins were detected by immunoblotting as previously described (Fleming et al., 2005). 

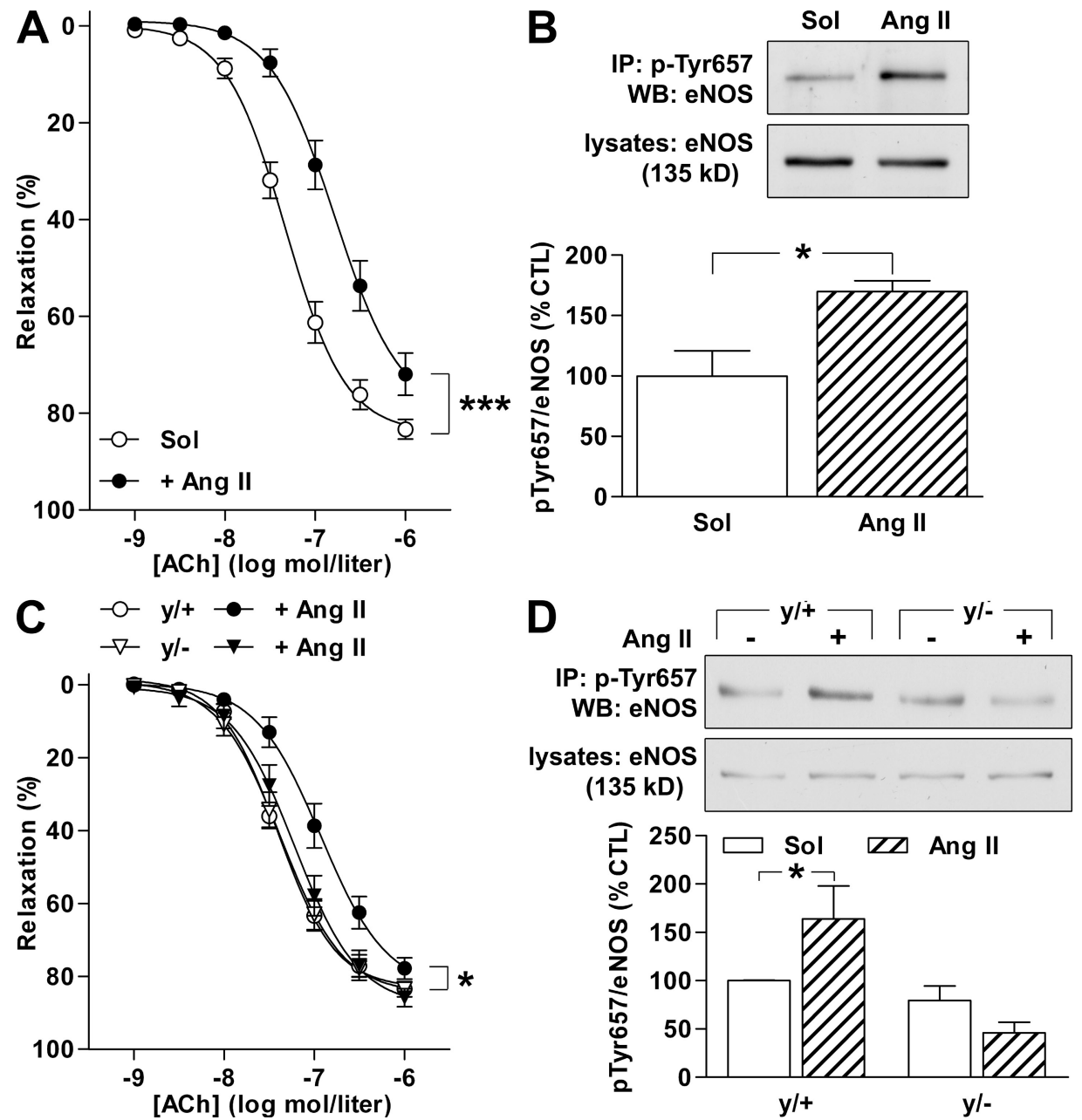

Figure 6. Chronic Ang II infusion induces Tyr657 phosphorylation of eNOS in wild-type but not in Nox2y/- mice. (A-D) Wild-type mice $(A$ and $B)$, and Nox2 ${ }^{\mathrm{y} /-}$ mice $(\mathrm{y} /-$ ) or the corresponding wild-type littermates $(\mathrm{y} /+; \mathrm{C}$ and $\mathrm{D})$ were treated with vehicle (Sol) or $1 \mathrm{mg} / \mathrm{kg} / \mathrm{day}$ Ang $\mathrm{II}$ for 3 wk, after which endothelium-dependent relaxation in response to ACh (A and C) and eNOS Tyr657 phosphorylation (B and D) were assessed in aortic segments. The graphs summarize data from eight mice per group stratified over two ( $A$ and $B$ ) or four ( $C$ and $D)$ independent experiments; immunoprecipitations (IP) were performed on lysates from two pooled aortae. Data are expressed as means $\pm \mathrm{SEM}$. ${ }^{*}, \mathrm{P}<0.05 ;$ and ${ }^{* * *}, \mathrm{P}<0.001$ versus the corresponding vehicle (Sol) control. WB, Western blotting.

Animal experiments. Animal experiments were approved by the Regierungspräsidium Darmstadt (F18/14). 6-9-wk-old male C57/b6 mice were obtained from Charles River. Male C57/b6 $\mathrm{eNOS}^{-/-}$mice (provided by A. Gödecke, Heinrich-Heine-Universität, Düsseldorf, Germany) and Nox $2^{y /-}$ mice (The Jackson Laboratory) were bred at the animal facilities at Frankfurt University. In a subgroup of 16 wild-type, $16 \mathrm{Nox} 2^{\mathrm{y} /-}$, and $16 \mathrm{Nox} 2^{\mathrm{y} /+}$ mice, osmotic mini-pumps (ALZET) delivering either vehicle $(0.9 \% \mathrm{NaCl}$; 8 animals per group) or [ $\left.{ }^{5} \mathrm{val}\right]-$ Ang II $(1 \mathrm{mg} / \mathrm{kg} /$ day for $3 \mathrm{wk} ; 8$ animals per group) were implanted subcutaneously under isoflurane anesthesia.

Adenoviruses encoding GFP, wild-type eNOS, Y657F eNOS, or DN PYK2 were generated and delivered to the endothelial layer of carotid arteries from wild-type or eNOS ${ }^{-/-}$mice, as described previously (Dixit et al., 2005; Fisslthaler et al., 2008). In brief, mice were euthanized with isoflurane, and the aortic arches and carotid arteries were prepared free of adhering tissue but left in situ. Each vessel was filled with MCDB 131 containing $2 \%$ FCS (FBS GOLD; PAA) and viral particles $\left(1.5 \times 10^{8} \mathrm{PFU} / \mathrm{ml}\right)$. The vessel was slightly pressurized, ligated at both ends, and incubated in medium containing $2 \% \mathrm{FCS}$ for $4 \mathrm{~h}$. After the initial incubation, the ligatures were removed and the vessel was maintained in tissue culture for an additional 40-44 h. 3-mm aortic or carotid artery rings were connected to isometric force transducers at a resting force of 1 or $0.5 \mathrm{~g}$, respectively, for standard organ chamber experiments. Relaxations to cumulatively increasing concentrations of ACh were recorded in vessels preconstricted to $80 \%$ of the maximal $\mathrm{KCl}(80 \mathrm{mmol} /$ liter)-induced contraction using phenylephrine. All experiments were performed in the presence of $10 \mu \mathrm{mol} /$ liter diclofenac, and relaxations are denoted in the figures as the percentage of the maximal relaxation obtained by $10 \mu \mathrm{mol} /$ liter sodium nitroprusside.

Statistical analysis. Data are expressed as means \pm SEM. Statistical evaluation was performed on the absolute values or on log-transformed data with the Student's $t$ test for unpaired data, one-way analysis of variance (ANOVA) followed by a Bonferroni $t$ test, or ANOVA for repeated measures where appropriate. $\mathrm{P}<0.05$ was considered statistically significant.

Online supplemental material. Fig. S1 shows the Ang II-induced production of $\mathrm{H}_{2} \mathrm{O}_{2}$ in cultured endothelial cells. Fig. $\mathrm{S} 2$ shows the endogenous production of $\mathrm{H}_{2} \mathrm{O}_{2}$ in carotid arteries kept in tissue culture. Online supplemental material is available at http://www.jem.org/cgi/content/full/jem $.20090449 / \mathrm{DC} 1$. 
The authors are indebted to I. Winter, K. Bruch, and M. Piepenbrock for expert technical assistance.

This study was supported by EICOSANOX, an integrated project under the European Commission Framework 6 Program (contract LSHM-CT-2004-005033); by the Deutsche Forschungsgemeinschaft (Exzellenzcluster 147 "Cardio-Pulmonary Systems"); and by a young investigator grant from the Johann Wolfgang Goethe University (to A.E. Loot).

The authors have no conflicting financial interests.

Submitted: 25 February 2009

Accepted: 28 October 2009

\section{REFERENCES}

Blaukat, A., I. Ivankovic-Dikic, E. Grönroos, F. Dolfi, G. Tokiwa, K. Vuori, and I. Dikic. 1999. Adaptor proteins Grb2 and Crk couple Pyk2 with activation of specific mitogen-activated protein kinase cascades. J. Biol. Chem. 274:14893-14901. doi:10.1074/jbc.274.21.14893

Cai, H. 2005. Hydrogen peroxide regulation of endothelial function: origins, mechanisms, and consequences. Cardiovasc. Res. 68:26-36. doi:10.1016/ j.cardiores.2005.06.021

Chauhan, D., P. Pandey, T. Hideshima, S. Treon, N. Raje, F.E. Davies, Y. Shima, Y.T. Tai, S. Rosen, S. Avraham, et al. 2000. SHP2 mediates the protective effect of interleukin-6 against dexamethasone-induced apoptosis in multiple myeloma cells. J. Biol. Chem. 275:27845-27850.

Davignon, J., and P. Ganz. 2004. Role of endothelial dysfunction in atherosclerosis. Circulation. 109(Suppl. 1):III27-III32.

Dixit, M., A.E. Loot, A. Mohamed, B. Fisslthaler, C.M. Boulanger, B. Ceacareanu, A. Hassid, R. Busse, and I. Fleming. 2005. Gab1, SHP2, and protein kinase A are crucial for the activation of the endothelial NO synthase by fluid shear stress. Circ. Res. 97:1236-1244. doi:10.1161/01. RES.0000195611.59811.ab

Dossumbekova, A., E.V. Berdyshev, I. Gorshkova, Z. Shao, C. Li, P. Long, A. Joshi, V. Natarajan, and T.L. Vanden Hoek. 2008. Akt activates NOS3 and separately restores barrier integrity in $\mathrm{H}_{2} \mathrm{O}_{2}$-stressed human cardiac microvascular endothelium. Am. J. Physiol. Heart Circ. Physiol. 295:H2417-H2426. doi:10.1152/ajpheart.00501.2008

Edwards, D.H., Y. Li, and T.M. Griffith. 2008. Hydrogen peroxide potentiates the EDHF phenomenon by promoting endothelial $\mathrm{Ca}^{2+}$ mobilization. Arterioscler. Thromb. Vasc. Biol. 28:1774-1781. doi:10.1161/ ATVBAHA.108.172692

Fisslthaler, B., A.E. Loot, A. Mohamed, R. Busse, and I. Fleming. 2008. Inhibition of endothelial nitric oxide synthase activity by proline-rich tyrosine kinase 2 in response to fluid shear stress and insulin. Circ. Res. 102:1520-1528. doi:10.1161/CIRCRESAHA.108.172072

Fleming, I., B. Fisslthaler, M. Dixit, and R. Busse. 2005. Role of PECAM-1 in the shear-stress-induced activation of Akt and the endothelial nitric oxide synthase (eNOS) in endothelial cells. J. Cell Sci. 118:4103-4111. doi:10.1242/jcs.02541

Garrido, A.M., and K.K. Griendling. 2009. NADPH oxidases and angiotensin II receptor signaling. Mol. Cell. Endocrinol. 302:148-158. doi:10.1016/j.mce.2008.11.003

Jung, O., J.G. Schreiber, H. Geiger, T. Pedrazzini, R. Busse, and R.P. Brandes. 2004. gp91 phox-containing NADPH oxidase mediates endothelial dysfunction in renovascular hypertension. Circulation. 109:17951801. doi:10.1161/01.CIR.0000124223.00113.A4

Jung, O., R.P. Brandes, I.H. Kim, F. Schweda, R. Schmidt, B.D. Hammock, R. Busse, and I. Fleming. 2005. Soluble epoxide hydrolase is a main effector of angiotensin II-induced hypertension. Hypertension. 45:759765. doi:10.1161/01.HYP.0000153792.29478.1d

Landmesser, U., S. Dikalov, S.R. Price, L. McCann, T. Fukai, S.M. Holland, W.E. Mitch, and D.G. Harrison. 2003. Oxidation of tetrahydrobiopterin leads to uncoupling of endothelial cell nitric oxide synthase in hypertension. J. Clin. Invest. 111:1201-1209.

Largiadèr, T., M. Eto, S.K. Payeli, H. Greutert, H. Viswambharan, M. Lachat, G. Zünd, Z. Yang, F.C. Tanner, and T.F. Lüscher. 2008 Endothelial nitric oxide synthase gene transfer inhibits human smooth muscle cell migration via inhibition of Rho A. J. Cardiovasc. Pharmacol. 52:369-374. doi:10.1097/FJC.0b013e31818953d0

Meurer, S., S. Pioch, S. Gross, and W. Müller-Esterl. 2005. Reactive oxygen species induce tyrosine phosphorylation of and Src kinase recruitment to NO-sensitive guanylyl cyclase. J. Biol. Chem. 280:33149-33156. doi:10.1074/jbc.M507565200

Schulz, E., T. Jansen, P. Wenzel, A. Daiber, and T. Münzel. 2008. Nitric oxide, tetrahydrobiopterin, oxidative stress, and endothelial dysfunction in hypertension. Antioxid. Redox Signal. 10:1115-1126. doi:10.1089/ars .2007 .1989

Tai, L.K., M. Okuda, J. Abe, C. Yan, and B.C. Berk. 2002. Fluid shear stress activates proline-rich tyrosine kinase via reactive oxygen species-dependent pathway. Arterioscler. Thromb. Vasc. Biol. 22:1790-1796. doi:10.1161/01. ATV.0000034475.40227.40

Tang, H., Q. Hao, S.A. Rutherford, B. Low, and Z.J. Zhao. 2005 Inactivation of SRC family tyrosine kinases by reactive oxygen species in vivo. J. Biol. Chem. 280:23918-23925. doi:10.1074/jbc.M503498200

Tanner, F.C., B. van der Loo, S. Shaw, H. Greutert, M.M. Bachschmid, M. Berrozpe, I. Rozenberg, N. Blau, R. Siebenmann, J. Schmidli, et al. 2007. Inactivity of nitric oxide synthase gene in the atherosclerotic human carotid artery. Basic Res. Cardiol. 102:308-317. doi:10.1007/s00395-007-0650-7

Thomas, S.R., K. Chen, and J.F. Keaney Jr. 2002. Hydrogen peroxide activates endothelial nitric-oxide synthase through coordinated phosphorylation and dephosphorylation via a phosphoinositide 3-kinase-dependent signaling pathway. J. Biol. Chem. 277:6017-6024. doi:10.1074/jbc.M109107200

Thomas, S.R., P.K. Witting, and G.R. Drummond. 2008. Redox control of endothelial function and dysfunction: molecular mechanisms and therapeutic opportunities. Antioxid. Redox Signal. 10:1713-1765. doi:10.1089/ ars. 2008.2027

Thomson, M.J., V. Puntmann, and J.C. Kaski. 2007. Atherosclerosis and oxidant stress: the end of the road for antioxidant vitamin treatment? Cardiovasc. Drugs Ther. 21:195-210. doi:10.1007/s10557-007-6027-1

Tribble, D.L., E.L. Gong, C. Leeuwenburgh, J.W. Heinecke, E.L. Carlson, J.G. Verstuyft, and C.J. Epstein. 1997. Fatty streak formation in fat-fed mice expressing human copper-zinc superoxide dismutase. Arterioscler. Thromb. Vasc. Biol. 17:1734-1740.

Ulker, S., D. McMaster, P.P. McKeown, and U. Bayraktutan. 2003. Impaired activities of antioxidant enzymes elicit endothelial dysfunction in spontaneous hypertensive rats despite enhanced vascular nitric oxide generation. Cardiovasc. Res. 59:488-500. doi:10.1016/S0008-6363(03)00424-3

Yin, G., C. Yan, and B.C. Berk. 2003. Angiotensin II signaling pathways mediated by tyrosine kinases. Int. J. Biochem. Cell Biol. 35:780-783. doi:10.1016/S1357-2725(02)00300-X

Zanetti, M., J. Sato, C.J. Jost, P. Gloviczki, Z.S. Katusic, and T. O’Brien. 2001. Gene transfer of manganese superoxide dismutase reverses vascular dysfunction in the absence but not in the presence of atherosclerotic plaque. Hum. Gene Ther. 12:1407-1416. doi:10.1089/104303401750298562 
SUPPLEMENTAL MATERIAL

Loot et al., http://www.jem.org/cgi/content/full/jem.20090449/DC1

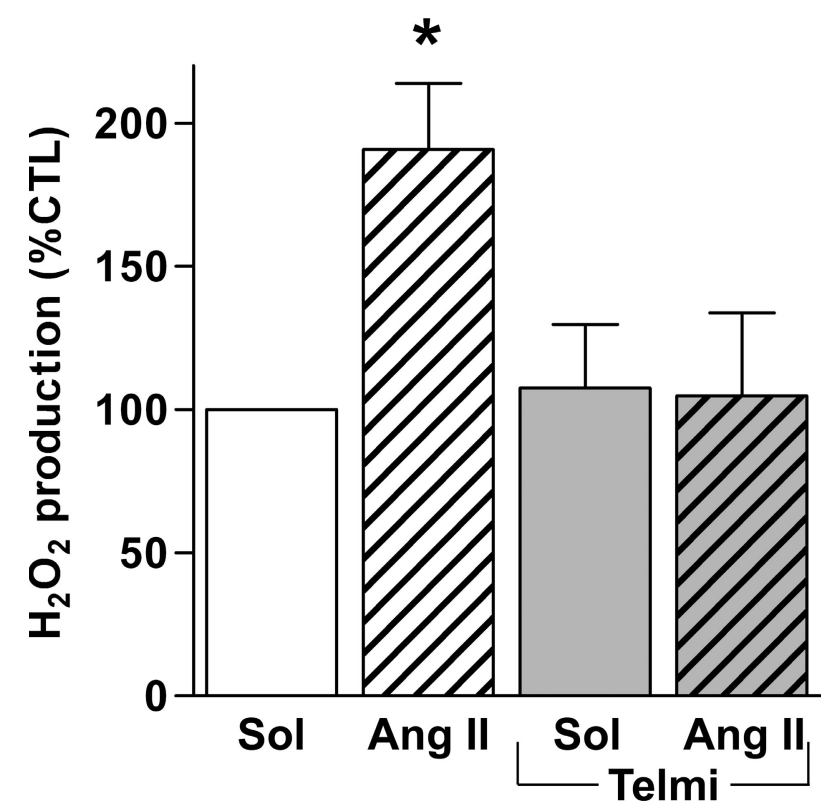

Figure S1. Ang II induces $\mathrm{H}_{2} \mathrm{O}_{2}$ production in cultured endothelial cells. Mouse endothelial cells were incubated in modified Tyrode's solution con-

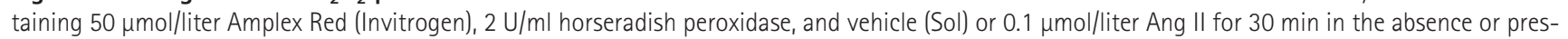
ence of $10 \mu \mathrm{mol} /$ liter of the $A T_{1}$ receptor antagonist telmisartan (Telmi). After incubation for $30 \mathrm{~min}$ at $37^{\circ} \mathrm{C}$, production of the fluorescent product was measured ( $540 \mathrm{~nm}$ excitation, $570 \mathrm{~nm}$ emission) as a measure of $\mathrm{H}_{2} \mathrm{O}_{2}$ production. The graph summarizes data from three independent experiments, each performed in triplicate. Data are expressed as means \pm SEM. ${ }^{*}, \mathrm{P}<0.05$ versus CTL. 

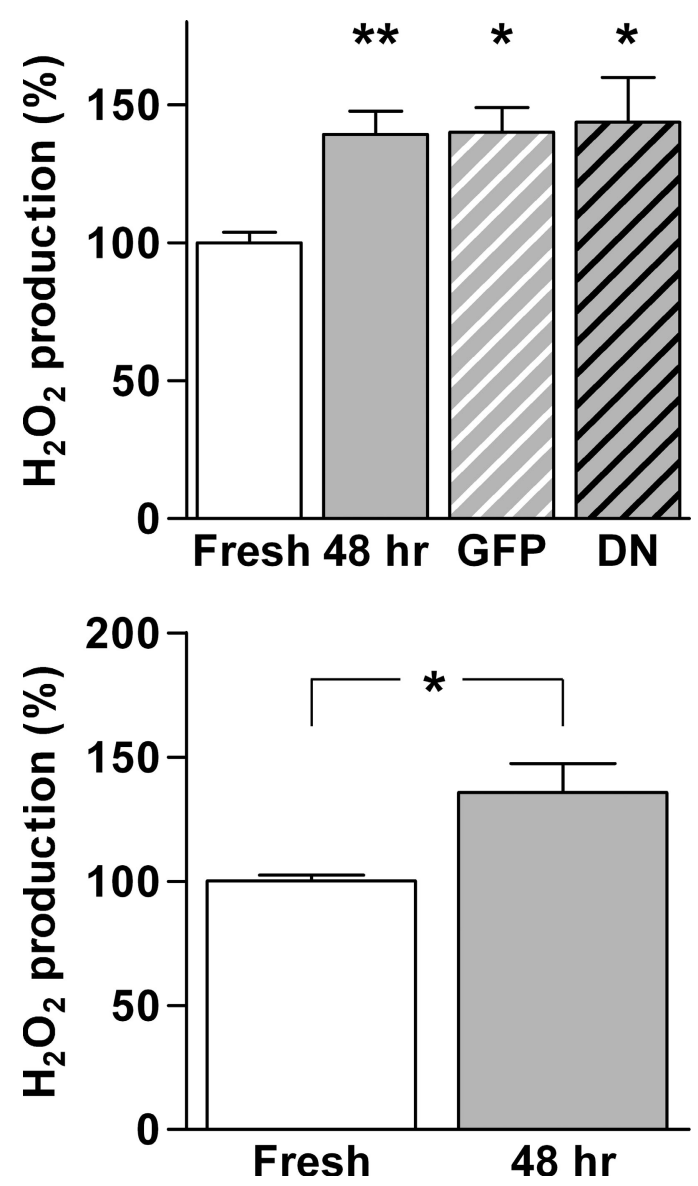

Figure S2. $\quad \mathrm{H}_{2} \mathrm{O}_{2}$ production in cultured vessels. $\mathrm{H}_{2} \mathrm{O}_{2}$ production was measured in 4-mm segments of carotid arteries from (top) wild-type and (bottom) eNOS ${ }^{-1-}$ mice that were either freshly isolated or maintained in tissue culture for $48 \mathrm{~h}$. Some of the cultured wild-type arteries were previously infected with adenoviruses expressing GFP or a DN PYK2 mutant. $\mathrm{H}_{2} \mathrm{O}_{2}$ production was expressed as the percentage of the production in freshly isolated vessels. The graphs summarize the results of six to nine segments. Data are expressed as means $\pm \mathrm{SEM} .{ }^{*}, \mathrm{P}<0.05$; and ${ }^{* *}, \mathrm{P}<0.01$ versus freshly isolated arteries. 